Research Article

\title{
Use of AFLP and RAPD molecular genetic markers and cytogenetic analysis to explore relationships among taxa of the Patagonian Bromus setifolius complex
}

\author{
Ana M. García ${ }^{1}$, Gustavo E. Schrauf ${ }^{2}$, Graciela González ${ }^{1}$, Lidia Poggio ${ }^{1}$, Carlos A. Naranjo ${ }^{3 \dagger}$, \\ Marck P. Dupal ${ }^{4}$, Germán C. Spangenberg ${ }^{4}$ and John W. Forster ${ }^{4}$ \\ ${ }^{I}$ Facultad de Ciencias Exactas y Naturales, Universidad de Buenos Aires, Buenos Aires, Argentina. \\ ${ }^{2}$ Facultad de Agronomía, Universidad de Buenos Aires, Buenos Aires, Argentina. \\ ${ }^{3}$ Instituto Fitotécnico de Santa Catalina, Llavallol, Argentina. \\ ${ }^{4}$ Primary Industries Research Victoria, Victorian AgriBiosciences Centre, Bundoora, Victoria, Australia.
}

\begin{abstract}
Bromus setifolius var. pictus (Hook) Skottsb., B. setifolius var. setifolius Presl. and B. setifolius var. brevifolius Ness are three native Patagonian taxa in the section Pnigma Dumort of the genus Bromus L. AFLP and RAPD analysis, in conjunction with genetic distance measurements and statistical techniques, revealed variation within this group and indicated that $B$. setifolius var. brevifolius was closely related to $B$. setifolius var. pictus, with both taxa being more distantly related to $B$. setifolius var. setifolius. Cytogenetic analysis confirmed the chromosomal number of $B$. setifolius var. pictus $(2 n=70)$ and $B$. setifolius var. setifolius $(2 n=28)$ and showed for the first time that $B$. setifolius var. brevifolius had $2 n=70$. The combination of molecular genetic and cytogenetic evidence supported a species status for two of the three taxa and suggested hypotheses for the evolutionary origin of these complex taxa. Species status was also indicated for $B$. setifolius var. setifolius. Based on these findings, we suggest that $B$. setifolius var. pictus be referred to as B. pictus Hook var. pictus, and B. setifolius var brevifolius as B. pictus Hook var brevifolius. The correlation between AFLP diversity and variation in ecological parameters suggested that this marker system could be used to assess breeding progress and to monitor the domestication of Patagonian Bromus species for agronomic use.
\end{abstract}

Key words: AFLP, Argentina, Bromus setifolius complex, cytogenetics, Patagonia, RAPD.

Received: May 16, 2008; Accepted: August 12, 2008.

\section{Introduction}

The genus Bromus L. contains approximately 150 species grouped into six taxonomic sections that are distributed throughout temperate regions of the world (Clayton and Renvoize, 1986). The section Pnigma includes about 60 species that are disseminated across Eurasia and North and South America (Smith, 1970). In Patagonia of South America, the section Pnigma is represented by B. setifolius Presl., which has been considered as a complex taxon because of its extensive morphological variation (Camara Hernandez, 1978; Matthei, 1986; Gutierrez and Pensiero, 1998). Three varieties of this species are recognized, namely, B. setifolius var. setifolius, B. setifolius var. pictus (Hook. F.) Skottsberg and B. setifolius var. brevifolius Ness.

Send correspondence to Gustavo E. Schrauf. Facultad de Agronomía, Universidad de Buenos Aires, Av. San Martín 4453, 1417 Buenos Aires, Argentina. E-mail: gschrauf@agro.uba.ar. ${ }^{\dagger}$ Deceased in 2005.
The semi-desert region of Patagonia is a large environmental niche that has been subjected to substantial degradation (Aguiar and Sala, 1998). Bare soils represent $\sim 60 \%$ of the total area, and a recent history of over-grazing has accelerated the process of desertification. Members of the $B$. setifolius complex could play an important role in the cessation and reversal of this environmental degradation (Aguiar and Sala, 1997). This is particularly true of $B$. setifolius var. pictus, which shows a favorable combination of drought resistance, high recruitment capacity and forage nutritive value. Bromus setifolius var. pictus and $B$. setifolius var. setifolius are sympatric inhabitants of the Patagonian semi-desert, whereas $B$. setifolius var. brevifolius is found in wetter grass steppe environments of the sub-Andean region (Naranjo et al., 1990; Gutierrez and Pensiero, 1998).

Naranjo et al. (1990) performed a biosystematic study of the two sympatric taxa $B$. setifolius var. setifolius and B. setifolius var. pictus. Numerical taxonomy based on cluster analysis and principal components analysis (PCA) 
of 35 exomorphological characters detected two phenetically distinct groups that corresponded to B. setifolius var. setifolius and $B$. setifolius var. pictus. Cytological examination of mitosis demonstrated that $B$. setifolius var. setifolius plants had a chromosomal composition of $2 \mathrm{n}=4 \mathrm{x}=28$, whereas $B$. setifolius var. pictus plants had a chromosomal composition of $2 \mathrm{n}=10 \mathrm{x}=70$. Other cytogenetic differences between the two taxa included the karyotypic formula, type of satellite chromosome, basic genome length, asymmetry, C-banding patterns, and meiotic chromosomal behavior.

Meiotic chromosomal pairing in B. setifolius var. setifolius indicated the formation of 14 bivalents, typical of an allotetraploid. In contrast, chromosomal pairing in $B$. setifolius var. pictus suggested segmental allodecaploid behavior, with the formation of 35 bivalents being the most frequent configuration. With regard to the breeding systems, cleistogamous and chasmogamous flowers were found in $B$. setifolius var. setifolius whereas only cleistogamous flowers were observed in B.setifolius var. pictus; morphological and cytological analyses revealed no hybrid individuals. The stable morphological features of both taxa, which paralleled the karyotypic differences between them, suggested that they should be recognized as separate species (Naranjo et al., 1990). Although several cytogenetic studies have been reported for taxa of the B. setifolius complex (Covas and Schnack, 1946; Stebbins, 1947; Covas and Hunziker, 1954; Naranjo et al., 1990), the chromosome number of $B$. setifolius var. brevifolius has not as yet been determined.

Robust delineation among taxa within B. setifolius is problematic (Gutierrez and Pensiero, 1998). The morphological traits that distinguish these taxa are not randomly selected and may consequently bias estimates of genetic distance among groups (Lewontin, 1974). In addition, the discontinuity of morphological characteristics is not always observed. Although the potential influence of environmental selection on adaptive traits is more readily understood for phenotypically-apparent traits than for cryptic markers such as DNA-based polymorphisms, genetic polymorphisms may nevertheless provide complementary data for detailed analysis of closely related genotypes.
Molecular genetic methods have been applied to plant biosystematics with considerable success (Doebley, 1992; Soltis and Soltis, 1998). Random amplified polymorphic DNA (RAPD; Williams et al., 1990) and amplified fragment length polymorphism (AFLP; Vos et al., 1995) are two PCR-based techniques that have been successfully applied to the identification and estimation of molecular genetic diversity in various species (Newbury and FordLloyd, 1993; Paran et al., 1998; Kolliker et al., 2001; Massa et al., 2001; Puecher et al., 2001). These techniques provide major advantages compared to other molecular marker methods such as restriction fragment length polymorphism (RFLP) because of their reduced requirement for large quantities of genomic DNA, their ability to amplify DNA from preserved tissues, and the smaller amount of time, labor and cost involved. In addition, unlike the PCRbased simple sequence repeat (SSR) and single nucleotide polymorphism (SNP) techniques, no prior sequence knowledge is required, and both RAPD and AFLP generate multiple locus information in a single assay (Wolfe and Liston, 1998). However, problems with reproducibility, particularly for RAPD, and the generation of dominant markers that are not locus-specific, limit the applicability of these methods, especially for genetic mapping studies compared to simple DNA profiling.

The aim of this study was to use molecular genetic and cytological approaches to examine the relationships among taxa of the $B$. setifolius complex. The results described here should be useful in elucidating the evolutionary processes that led to the origin of these taxa and should facilitate the domestication of forage grass species with potential agronomic value.

\section{Materials and Methods}

\section{Plant material}

Samples from different accessions of the section Pnigma were obtained from Patagonia, in Argentina (Table 1). The morphological variation of dried tussocks was used to classify each accession. Seeds obtained from different tussocks were planted in pots to produce plantlets

Table 1 - Classification of the samples used for molecular genetic marker analysis based on the species and variety, geographical origin, sample code and type of analysis.

\begin{tabular}{|c|c|c|c|}
\hline Species & Population & Code & Type of molecular marker analysis \\
\hline B. s. var. setifolius & Río Mayo & $B s 1$ & RAPD and AFLP \\
\hline B. s. var. brevifolius & San Martín de los Andes & $B b 1$ & RAPD and AFLP \\
\hline B. s. var. pictus & Río Mayo & $B p 1$ & RAPD \\
\hline B. s. var. pictus & Río Mayo (non-grazed 1) & $B p \mathrm{RMe} 1$ & AFLP \\
\hline B. s. var. pictus & Río Mayo (non-grazed 2) & $B p \mathrm{RMe} 2$ & AFLP \\
\hline B. s. var. pictus & Río Mayo (grazed 1) & $B p \mathrm{RMg} 1$ & AFLP \\
\hline B. s. var. pictus & Río Mayo (grazed 2) & $B p \mathrm{RMg} 2$ & AFLP \\
\hline B. s. var. pictus & Gobernador Costa & $B p \mathrm{GC}$ & AFLP \\
\hline B. catharticus & Control (outgroup) & $B c$ & AFLP \\
\hline
\end{tabular}


for analysis. RAPD and AFLP analyses were done on pooled samples from 20 plantlets of $B$. setifolius var. pictus $(B p 1), B$. setifolius var. brevifolius $(B b 1)$ and $B$. setifolius var. setifolius $(B s 1)$. Five accessions of $B$. setifolius var. pictus were included in the AFLP analysis. One was native to a region close to the Atlantic coast known as Gobernador Costa, and is denoted here as $B p \mathrm{GC}$. The other four accessions were native to the Rio Mayo region in the Patagonian shrub steppe located close to the Andes: two of the Rio Mayo accessions were from areas grazed predominantly by sheep (denoted here as $B p \mathrm{RMg} 1$ and $B p \mathrm{RMg} 2$ ), and two were from areas excluded from the grazing by large herbivores, sheep and guanacos (denoted as $B p R M e 1$ and $B p \mathrm{RMe} 2$ ). A pooled genotypic sample of B. catharticus Vahl. subsp. stamineus (Desv.) Massa $(2 n=42)$ from section Ceratochloa of the genus Bromus was obtained from humid microenvironments of Patagonia and used as a control (outgroup).

\section{RAPD and AFLP assays}

Young leaves from 20 plantlets of each accession were combined, snap frozen in liquid nitrogen and lyophilized for $48 \mathrm{~h}$. Subsequently, aluminum oxide crystals were added and the samples were ground to a fine powder with a pre-cooled pestle and mortar, prior to DNA extraction by the method of Saghai-Maroof et al. (1984).

The amplification reactions for RAPD analysis was done using different decamer oligonucleotide primers (Operon Technologies, Almeda, USA) in a DNA thermal cycler (Perkin Elmer). After an initial denaturation step at $94{ }^{\circ} \mathrm{C}, 42$ cycles of $45 \mathrm{~s}$ at $94{ }^{\circ} \mathrm{C}$ (denaturation), $60 \mathrm{~s}$ at $55^{\circ} \mathrm{C}$ (annealing), and $90 \mathrm{~s}$ at $72{ }^{\circ} \mathrm{C}$ (extension) were done prior to a final extension of $5 \mathrm{~min}$ at $72{ }^{\circ} \mathrm{C}$ and subsequent cooling to $4{ }^{\circ} \mathrm{C}$. The amplified products were visualized by staining with ethidium bromide $(0.5 \mu \mathrm{g} / \mathrm{mL})$ after electrophoresis at constant voltage $(60 \mathrm{~V})$ in $0.9 \%(\mathrm{w} / \mathrm{v})$ agarose gels in TAE (40 mM Tris-acetate plus $1 \mathrm{mM}$ EDTA) buffer. Seven microliters of the reaction mixture was added to $3 \mu \mathrm{L}$ of $1 \mathrm{x}$ gel loading buffer (Maniatis et al., 1982).

AFLP reactions were done as described by Vos et al. (1995) with appropriate modifications. For digestion, 2.0-3.0 $\mu \mathrm{g}$ of the target DNA, $1.25 \mu \mathrm{L}$ of EcoRI enzyme (12.5 units, $10 \mathrm{U} / \mu \mathrm{L}$ ) and $1.25 \mu \mathrm{L}$ of MseI enzyme (12.5 units, $10 \mathrm{U} / \mu \mathrm{L}$ ) were used in a reaction volume of $50 \mu \mathrm{L}$. Adaptors specific for each restriction enzyme terminus were ligated to the digested DNA fragments in a final volume of $60 \mu \mathrm{L}$ followed by incubation at $37^{\circ} \mathrm{C}$ for $5-6 \mathrm{~h}$. Primary amplification by PCR was done using a $+0 /+0$ primer combination and 30 cycles of $94^{\circ} \mathrm{C}$ for $30 \mathrm{~s}, 56^{\circ} \mathrm{C}$ for $60 \mathrm{~s}$ and $72{ }^{\circ} \mathrm{C}$ for $60 \mathrm{~s}$. Diluted primary amplification product was selectively amplified by using $1 \mu \mathrm{L}$ aliquots of the selected primer specific for the frequent-cutter restriction enzyme MseI (30 $\mathrm{ng} / \mu \mathrm{L})$ and the rare-cutter restriction enzyme (EcoRI) $(5 \mathrm{ng} / \mu \mathrm{L})$. The primer for $E c o R l$ was end- labelled with $\gamma^{33} \mathrm{P}$-ATP to allow autoradiographic detection of AFLP products. The primer combinations used for EcoRI/MseI were: (1) AAA/GGGT, (2) AAG/GGGT, (3) $\mathrm{AAG} / \mathrm{CCA}$, (4) $\mathrm{AAC} / \mathrm{CCA}$, (5) $\mathrm{AAC} / \mathrm{GGG}$, (6) AAC/AAA, (7) AAA/CCA and (8) AAG/CAA. Selective amplification was done using the following touchdown PCR conditions: cycle $1: 94^{\circ} \mathrm{C}$ for $30 \mathrm{~s}, 65^{\circ} \mathrm{C}$ for $30 \mathrm{~s}$ and $72{ }^{\circ} \mathrm{C}$ for $60 \mathrm{~s}$; cycles $2-13: 94{ }^{\circ} \mathrm{C}$ for $30 \mathrm{~s}, 65^{\circ} \mathrm{C}$ for $30 \mathrm{~s}$, with a $0.7^{\circ} \mathrm{C}$ decrease in each cycle, and $72{ }^{\circ} \mathrm{C}$ for $60 \mathrm{~s}$; cycles $14-36$ : $94{ }^{\circ} \mathrm{C}$ for $30 \mathrm{~s}, 56^{\circ} \mathrm{C}$ for $30 \mathrm{~s}$ and $72{ }^{\circ} \mathrm{C}$ for $60 \mathrm{~s}$. After amplification, the sample was mixed with one volume of sequencing loading buffer, heated to $95^{\circ} \mathrm{C}$ for $5 \mathrm{~min}$ and briefly quenched on ice before the loading onto the gel. Samples were run on a $6 \%(\mathrm{w} / \mathrm{v})$ denaturing polyacrylamide gel (19:1 acrylamide:bis, w/w) in 7.6 M urea and 1x TBE buffer. Electrophoresis was done at constant power $(110 \mathrm{~W})$ for $\sim 2 \mathrm{~h}$, after which the gel was dried at $80^{\circ} \mathrm{C}$ for $40 \mathrm{~min}$ and analyzed by overnight exposure to a storage phosphor screen for phosphorimaging analysis (Molecular Dynamics).

\section{Analysis of molecular marker data}

RAPD and AFLP bands were treated as dominant genetic markers and scored as polymorphic features if present in some but not all accessions, and as monomorphic features when the band was present in all of the accessions evaluated. To avoid underestimating the genetic similarity, the monomorphic and polymorphic bands were both included in the analysis. For RAPD data, genetic distance was estimated using the index of Balakrishnan and Sanghvi (1968). Matrices generated by scoring the AFLP bands were used as input data for the application NTSYS-pc version 2.01 (Rohlf, 1988). The Jaccard similarity index was applied using the SAHN program of NTSYS, and cluster analysis by UPGMA (unweighted pair-group method with arithmetic averages) was used done to obtain dendrograms. The data was also used for multidimensional principal coordinate analysis (PCOA).

\section{Cytogenetic analysis}

Chromosomal number and morphology were determined in mitotic metaphases of 20 plants from each accession (B. setifolius var. setifolius, B. setifolius var. brevifolius and $B$. setifolius var. pictus; $B s 1, B b 1$ and $B p 1$, respectively). Seeds from accessions $B s 1, B b 1$ and $B p 1$ were placed on wet filter paper in Petri dishes. Root tips were incubated in ice water for $36 \mathrm{~h}$, fixed in ethanol-glacial acetic acid $(3: 1, \mathrm{v} / \mathrm{v})$ for 2 days at $4{ }^{\circ} \mathrm{C}$, and then transferred to $70 \%$ ethanol and refrigerated until analyzed. Squashed preparations were prepared in $2 \%$ hematoxylin in acetic acid and examined with a Zeiss Axiophot microscope. Photographs were taken with Kodak T-Max-100 film. 


\section{Results}

\section{RAPD analysis}

Of the 20 decamer RAPD primers that were tested for PCR amplification, 11 yielded clear, reproducible amplification profiles with the three pooled accessions. Thirtythree of 41 clearly distinguished bands were polymorphic (Figure 1). Calculation of the genetic distances showed that $B$. setifolius var. pictus and B. setifolius var. brevifolius were closer to each other than either was to B. setifolius var. setifolius (Table 2).

\section{AFLP analysis}

The amplification profiles obtained with different AFLP primer combinations in the seven samples corresponding to different accessions were used to score 692 fragments. The number of bands in each accession differed among taxa, with $B$ setifolius var. setifolius having a lower number of bands (439) than B. setifolius var. brevifolus (466) and B. setifolius var. pictus (an average of 471). Within B. setifolius var. pictus, accessions obtained from grazed areas had a lower number of bands (466) than accessions from non-grazed areas (an average of 477). Two hundred and seventy-seven bands were monomorphic among the taxa and 415 bands were polymorphic. Among the polymorphic bands, 153 were exclusive to a single taxon: $B$.

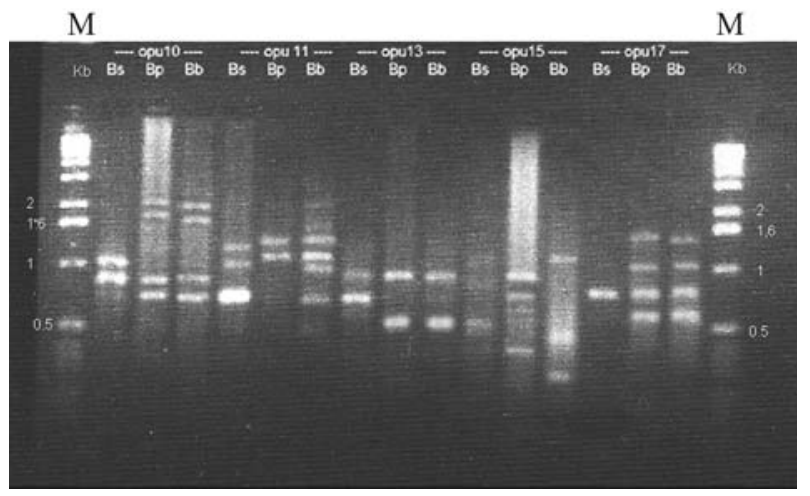

Figure 1 - RAPD electrophoretic profiles from pooled samples of $B$. setifolius var. setifolius $(B s), B$. setifolius var. pictus $(B p)$ and $B$. setifolius var. brevifolius $(B b)$ based on five primers (opu10: 5'-ACCTCGGCAC3', opu11: 5'-AGACCCAGAG-3', opu13: 5'-GGCTGGTTCC-3', opu15: 5'-ACGGGCCAGT-3', opu17: 5'-ACCTGGGGAG-3'). Molecular size markers are indicated $(\mathrm{M}=1 \mathrm{~kb}$ DNA ladder $)$.

Table 2 - Genetic distances among accessions of Bromus in the section Pnigma, based on RAPD analysis of pooled samples. The distances were calculated as described by Balakrishnan and Sanghvi (1968).

\begin{tabular}{lccc}
\hline & $\begin{array}{c}\text { B. s. } \\
\text { var. pictus }\end{array}$ & $\begin{array}{c}\text { B. s. var. } \\
\text { brevifolius }\end{array}$ & $\begin{array}{c}\text { B. s. var. } \\
\text { setifolius }\end{array}$ \\
\hline B. s. var. pictus (Bp1) & 0 & - & - \\
B. s. var. brevifolius (Bb1) & 37.9 & 0 & - \\
B. s. var. setifolius (Bs1) & 56.1 & 68.2 & 0 \\
\hline
\end{tabular}

setifolius var. setifolius had 100 exclusive bands, $B$. setifolius var. brevifolius 35 and B. setifolius var. pictus 18 . Within B. setifolius var. pictus, 429 bands were monomorphic and 84 were polymorphic. A comparison of the amplification profiles among accessions in this taxon allowed the identification of accession-prevalent and species-prevalent markers (Figure 2).

Samples $B p R M g 1$ and $B s 1$ were from the same location and, in some cases, the same tussock included both species. In contrast, in the other species, individual tussocks contained only one species, but generally included plants with more than one genotype for the species. The genetic distances among the samples analyzed by AFLP were calculated by using the Jaccard similarity coefficient (Table 3). The degree of similarity among the five accessions of $B$. setifolius var. pictus was high (0.834-0.988). Figure 3 shows the dendrogram obtained by cluster analysis of the similarity indexes using the UPGMA method (Figure 3).

The pooled sample of $B$. catharticus genotypes was clearly separated from accessions of the section Pnigma, thus confirming that $B$. catharticus was an outgroup in this analysis. The three taxa within section Pnigma were grouped in a single large cluster. Within B. setifolius var. pictus, accessions from the same geographical area (Rio Mayo) were grouped in the same sub-cluster. Two additional sub-clusters were identified in accessions from this geographical location and differed in their grazing history.

Figure 4 shows a 3-dimensional plot of the AFLP data based on multidimensional PCOA. The first principal coordinate (depicted by the length of the rectangle in Figure 4) explained $51.58 \%$ of the total variation and separated $B$. setifolius var. setifolius from B. setifolius var. pictus and $B$. setifolius var. brevifolius. The second principal coordinate (depicted by the width of the rectangle) explained $21.52 \%$ of the variation and separated B. setifolius var. brevifolius

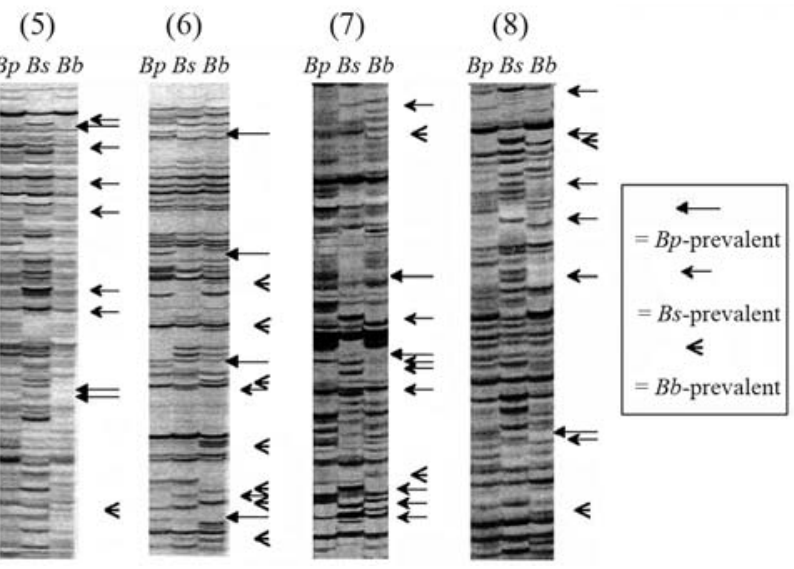

Figure 2 - AFLP electrophoretic profiles from pooled samples of $B$. setifolius var. pictus $(B p), B$. setifolius var. setifolius $(B s)$ and $B$. setifolius var. brevifolius (Bb) based on EcoRI/MseI primer combinations (5), (6), (7) and (8). Arrows indicate species-prevalent markers. 
Table 3 - Genetic distances among accessions of Bromus in the section Pnigma, based on AFLP analysis of pooled samples. The distances were calculated by using the Jaccard similarity coefficient.

\begin{tabular}{lccccccc}
\hline Accession & $B p \mathrm{RMg} 1$ & $B p \mathrm{RMg} 2$ & $B p \mathrm{RMc} 1$ & $B p \mathrm{RMc} 2$ & $B p \mathrm{GC}$ & $B s 1$ & $B b 1$ \\
\hline$B p \mathrm{RMg} 1$ & 1 & - & & & & & \\
$B p \mathrm{RMg} 2$ & 0.988 & 1 & & & & & \\
$B p \mathrm{RMe} 1$ & 0.924 & 0.927 & 1 & & & & \\
$B p \mathrm{RMe} 2$ & 0.927 & 0.930 & 0.943 & 1 & & & \\
$B p \mathrm{GC}$ & 0.834 & 0.841 & 0.863 & 0.839 & 1 & & \\
$B s 1$ & 0.529 & 0.530 & 0.506 & 0.521 & 0.502 & 1 & \\
$B b 1$ & 0.783 & 0.786 & 0.777 & 0.805 & 0.719 & 0.485 & 1 \\
\hline
\end{tabular}

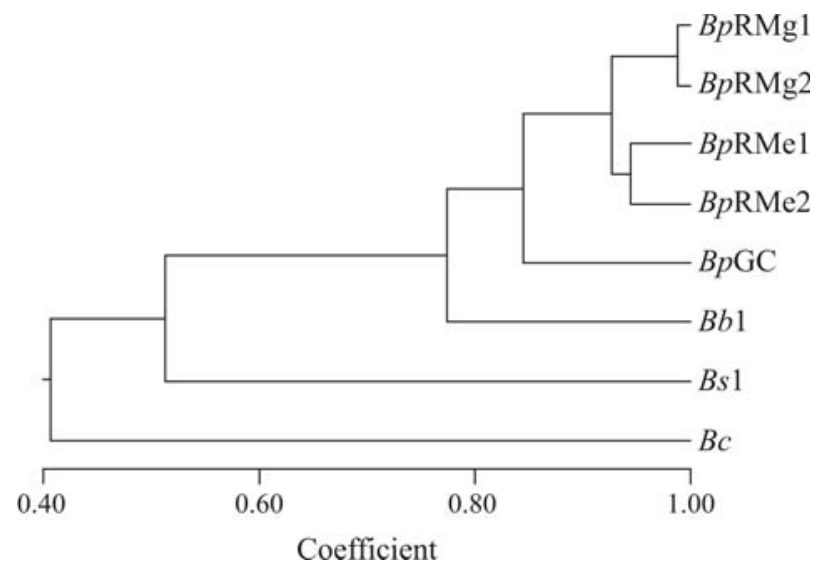

Figure 3 - UPGMA dendrogram for $B$. setifolius var. setifolius $(B s 1), B$. setifolius var. brevifolius $(B b 1)$ and $B$. setifolius var. pictus $(B p)$ accessions and the $B$. catharticus control $(B C)$. The Jaccard similarity coefficients of AFLP marker data were used to construct the dendrogram.

sample from B. setfolius var. pictus and B. setifolius var. setifolius. The third principal coordinate (depicted by the height of the bars) explained $15.03 \%$ of the variation and discriminated between the populations of B. setifolius var. pictus. Each coordinate in multidimensional PCOA corresponded to a new variable associated with geneticallyrelated interspecific differences identified by AFLP analysis, and indicated that the greatest genetic divergence was between the B. setifolius var. brevifolius and B. setifolius var. setifolius samples (Table 3).

\section{Cytogenetic analysis}

Cytogenetic analysis revealed chromosomal numbers of $2 \mathrm{n}=28$ for B. setifolius var. setifolius, $2 \mathrm{n}=70$ for $B$. setifolius var. pictus and $2 \mathrm{n}=70$ for $B$. setifolius var. brevifolius (Figure 5).

\section{Discussion}

\section{Molecular marker-based genetic diversity analysis}

RAPD and AFLP analyses of taxa in the genus Bromus (section Pnigma) yielded similar results. Although difficulties associated with the reproducibility of RAPD

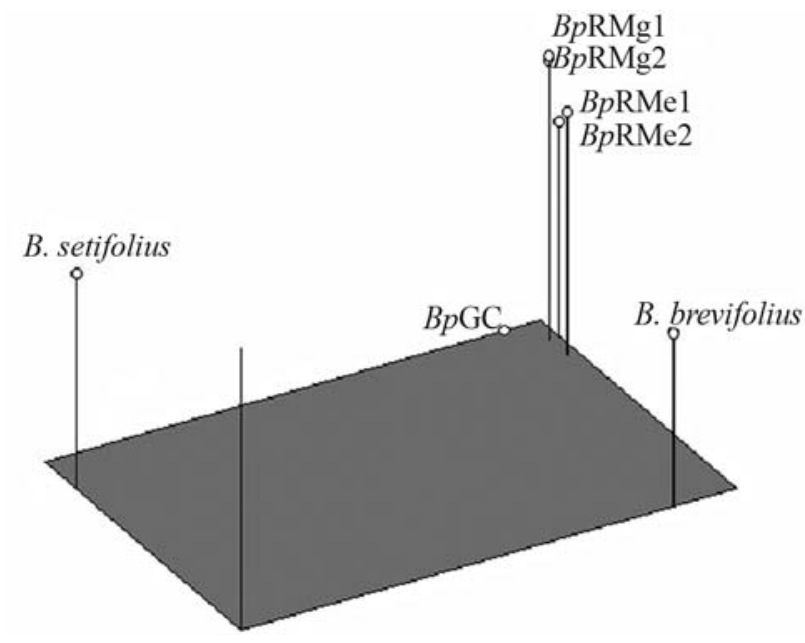

Figure 4 - PCOA 3-D plot for B. setifolius var. setifolius $(B s 1), B$. setifolius var. brevifolius $(B b 1)$ and $B$. setifolius var. pictus $(B p)$ accessions and the $B$. catharticus control $(B C)$, based on the Jaccard similarity coefficients for AFLP marker data.

limit the applicability of this technique (Perez et al., 1998), RAPD may nevertheless be useful for preliminary assessments of intraspecific, interspecific and intergeneric genetic variation in grasses (Wang et al., 2001; Garcia et al., 2004). In contrast, the greater accuracy and information content of AFLP make this technique more useful for detailed investigations such as in molecular breeding.

The variation in the number of bands among accessions was relatively small when compared to the large differences in chromosome numbers among taxa. Despite its lower chromosome number the tetraploid taxon $B$. setifolius var. setifolius had only $6.7 \%$ fewer bands than the decaploid taxon B. setifolius var. pictus. The higher content of genomic DNA in $B$. setifolius var. setifolius (1 $\mathrm{CX}=2.06 \mathrm{pg})$ compared to B. setifolius var. pictus (1 Cx $=1.63 \mathrm{pg})$ (Naranjo et al., 1990) may compensate for the lower chromosome number and account for the complexity of its AFLP profile. Fay et al. (2005) reported that the number of AFLP bands tended to increase up to a DNA content of $1 \mathrm{C}=8.43 \mathrm{pg}$. 


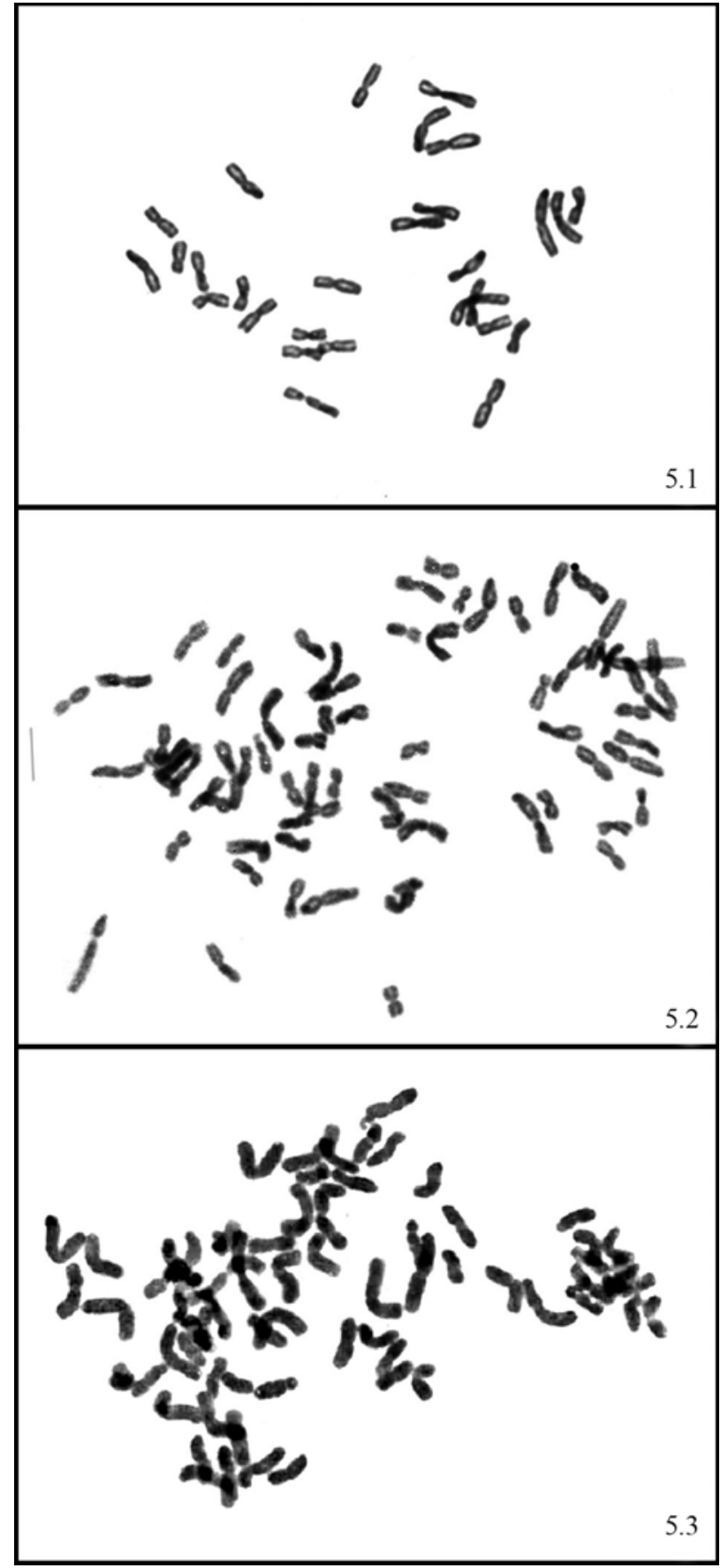

Figure 5 - Photomicrographs of root tip metaphase chromosomes. 5.1 Bromus setifolius var. setifolius $(2 \mathrm{n}=28), 5.2$ - Bromus setifolius var. pictus $(2 \mathrm{n}=70), 5.3$ - Bromus setifolius var. brevifolius $(2 \mathrm{n}=70)$. Scale bar $=10 \mu \mathrm{m}$.

Bromus setifolius var. pictus and B. setifolius var. brevifolius were more similar to each other than either was to $B$. setifolius var. setifolius. This observation is consistent with studies of morphological variation in which $B$. setifolius var. pictus and B.setifolius var. brevifolius showed a high degree of similarity and were difficult to distinguish taxonomically (Camara Hernandez, 1978). Al- though variation in the morphological traits did not permit a clear delineation between the taxa (Gutiérrez and Pensiero, 1998), both RAPD and AFLP analysis revealed bands that may be considered as taxon-specific discriminatory markers. This was particularly the case in the AFLP profiles. However, these results must be treated as preliminary until a larger number of accessions have been analyzed. AFLP analysis showed that very low frequencies in one taxon and very high frequencies in another may be readily misclassified as diagnostic bands because of the small sample sizes involved. Consequently, such features may be more accurately described as taxon-prevalent and require more intensive analysis.

Analysis of the genetic structure of plant populations requires the sampling of individual plants. In grasses of the genus Bromus, it is conventional to consider each tussock as an individual genotype, but it is also possible for individual tillers in a single tussock to be derived from different individuals of the same species, or even from different species. Wind damage on the Patagonian steppe produces high mortality during seedling recruitment (Aguiar and Sala, 1997). Consequenly, long-established tussocks may provide a 'nurse effect' by protecting the seedlings against wind. The composite content of individual tussocks is a potentially important confounding factor in the study of genetic diversity and may also provide an explanation for some of the difficulties previously encountered in the taxonomic discrimination of related species. The use of individual inflorescences as the unit of study, rather than the entire tussock, provides a way to address this problem.

\section{Relationships between genetic variation and ecological parameters}

In grass species there is not always a correlation between variation in morphological traits, geographical distribution, life history traits and biochemical or molecular genetic data. The lack of such correlations for $B$. catharticus was explained in terms of phenotypic plasticity (Puecher et al., 2001). In the grass Schizachyrium scoparium (Carman and Briske, 1985) morphological differences were detected between populations that had been subjected to long-term grazing and those that had not been grazed, but isoenzyme variation was not related to grazing history. Schrauf and Naranjo (1988) attributed the observed differences in isozenzyme frequencies between grazed and non-grazed populations of Pappophorum caespitosum and $P$. philippianum to the random effects of genetic drift.

As shown here, accessions of $B$. setifolius var. pictus with different grazing histories were resolved into different sub-clusters based on AFLP data. In addition, non-grazed accessions had more AFLP bands than those that had been grazed. These results may have several explanations. Sheep, as the primary grazing animals in this study, may have a more selective grazing behavior than bison (Carman 
and Briske, 1985) and cows (Schrauf and Naranjo, 1988), as found for Danthonia species (Scott and Whalley, 1984). Alternatively, the wider range of markers analyzed by AFLP makes this system more capable of assessing a more representative sample of genomic variation than isoenzymes, thereby allowing finer discrimination among accessions.

\section{Cytogenetic analysis and evolutionary relationships}

Kozuharov et al. (1981) showed that diploid, tetraploid and higher polyploid level chromosomal races within the annual Bromus species B. secalinus and B. lanceolatus were morphologically similar and that there was little justification for their taxonomic separation. In contrast, the perennial octoploid species B. lacmonicus and the diploid species $B$. parilicus are morphologically similar but show features that reflect their cytological differences and consequently justify their species status. Similarly, B. setifolius var. setifolius $(2 \mathrm{n}=28)$ and B. setifolius var. pictus $(2 \mathrm{n}=70)$ are perennial taxa with stable morphological differences that parallel their karyotypic divergence and support their classification as separate species.

Naranjo et al. (1990) proposed that $B$. setifolius var. setifolius (sensu Naranjo et al. (1990): B. setifolius) may be a progenitor taxon of the polyploid B. setifolius var pictus (sensu Naranjo et al. (1990): B. pictus) on their morphological similarity, karyotypic structure, growth pattern, breeding system and presence of reproductive isolation. Recent work using fluorescence in situ hybridization with total genomic DNA as a probe (GISH) has shown that $B$. setifolius var. setifolius or a closely related taxon is one of the progenitors of B. setifolius var. pictus, thus confirming the allopolyploid nature of this species (Garcia et al., 2005).

This report is the first to describe the chromosomal number of B. setifolius var. brevifolius $(2 \mathrm{n}=70)$. As shown here, molecular genetic data indicated a close relationship between $B$. setifolius var. brevifolius and $B$. setifolius var. pictus, and AFLP-based PCOA suggested that $B$. setifolius var. brevifolius may be directly derived from $B$. setifolius var. pictus, rather than the second allopolyploid progenitor, in agreement with the morphophysiological reticular pattern (Garcia et al., 2001). Bromus setifolius var. brevifolius has wide leaves and a fast initial growth, $B$. setifolius var. setifolius has short internodes and high drought resistance, and B. setifolius var. pictus has wide leaves, short internodes, fast initial growth and high drought resistance. The putative progenitor of $B$. setifolius var. pictus may have had a haploid chromosomal complement of $\mathrm{n}=21$, assuming that $B$. setifolius var. pictus has retained the genetic complement of both ancestral species (some chromosomal rearrangements may have occurred subsequent to polyploid formation). Additional studies are required to determine the identity of this progenitor.

\section{Conclusions and agronomic implications}

A taxonomic realignment of Bromus species within section Ceratochloa has been proposed based on morphological, cytological and molecular genetic data (Massa et al., 2004). The molecular genetic and cytogenetic data described here have clarified the relationships among taxa of the Patagonian Bromus section Pnigma. These data agree with the findings of Naranjo et al. (1990). Taxonomically, $B$ setifolius var. setifolius and B. setifolius var. pictus should be recognized as distinct species under the names $B$. setifolius Presl. and B. pictus Hook, respectively. The cytological and molecular genetic similarity between $B$. setifolius var. pictus and B. setifolius var. brevifolius suggests that these taxa be considered as varieties within the same species, i.e., B. pictus var. pictus and B. pictus var. brevifolius, respectively.

Bromus pictus var. pictus is currently the most attractive option for a cultivated species to mediate the reversal of environmental degradation in Patagonia because of its combination of drought tolerance, high recruitment capacity and forage quality. Biodiversity conservation issues may also be addressed through domestication and improved breeding of $B$. pictus var. pictus, particularly since genetic erosion through sheep grazing has pushed species of the section Pnigma to the brink of extinction. The genetic conservation of B. pictus var. pictus will prove effective for the section as a whole, and the initial data described here for molecular marker variation will provide valuable information for marker-assisted breeding and future evolutionary studies.

\section{Acknowledgments}

The authors thank V. Corcuera for helpful comments on the original manuscript, R. Golluscio, P. Maceda, M. Mercau and A. Sessa for help in collecting the plant material and D. Fink for help in preparing the figures. This research was supported by grants from the Consejo Nacional de Investigaciones Cientificas y Tecnicas (CONICET), Universidad de Buenos Aires (grant nos. TW01, G017 and AG097), and the Agencia Nacional de Promocion Cientifica y Tecnologica (grant no. PICT 14170), Argentina. Lidia Poggio and Carlos A. Naranjo (deceased in 2005) are career researchers of CONICET. In Australia, this work was supported by the Victorian Department of Primary Industries (DPI) and the Molecular Plant Breeding Cooperative Research Centre.

\section{References}

Aguiar MR and Sala OE (1997) Seed distribution constrains the dynamics of the Patagonian steppe. Ecology 78:93-100.

Aguiar MR and Sala OE (1998) Interactions among grasses, shrubs, and herbivores in Patagonia grass-shrub steppes. Ecol Aust 8:201-210. 
Balakrishnan V and Sanghvi D (1968) Distance between populations on the basis of attribute data. Biometrics 6:859-865.

Camara Hernandez J (1978) Bromus L. In: Nicora EG (ed) Flora Patagónica. Gramineae. V. 8. Colección Científica INTA, Buenos Aires, pp 77-93.

Carman JG and Briske DD (1985) Morphologic and allozymic variation between long term grazed and non-grazed populations of the bunchgrass Schizachyrium scoparium var. frequens. Oecologia 66:332-337.

Clayton WD and Renvoize SA (1986) Genera graminum. Grasses of the world. Kew Bull 13:1-389.

Covas G and Hunziker JH (1954) Estudios cariológicos en antófitas. IV parte. Rev Inv Agrop 8:249-253.

Covas G and Schnack B (1946) Números cromosómicos en antofitas de la región de Cuyo. Rev Arg Agron 13:153-166.

Doebley J (1992) Molecular systematics and crop evolution. In: Soltis PS, Soltis DE and Doyle JJ (eds) Molecular Systematics of Plants. Chapman and Hall, New York, pp 202-222.

Fay MF, Cowan RS and Leitch IJ (2005) The effects of nuclear DNA content (C2 value) on the quality and utility of AFLP fingerprints. Ann Bot 95:237-246.

Garcia AAF, Benchimol LL, Barbosa AMM, Geraldi IO, Souza Jr CL and Souza AP (2004) Comparison of RAPD, RFLP, AFLP and SSR markers for diversity studies in tropical maize inbred lines. Genet Mol Biol 27:579-588.

García AM, Schrauf GE, Naranjo CA and Poggio L (2001) Aportes al conocimiento del origen de Bromus pictus utilizando técnicas citogenéticas-moleculares. BAG J B Appl Genet 14:79.

García AM, Schrauf GE, González G, Poggio L, Naranjo CA, Dupal MP, Forster JW and Spangenberg GC (2005) Cytological and molecular approach to analyse Patagonian Bromus species. XVII International Botanical Congress, Vienna, pp 349.

Gutiérrez HF and Pensiero JF (1998) Sinopsis de las especies argentinas del género Bromus (Poaceae). Darwiniana 35:75-114.

Kolliker R, Jones ES, Jahufer MZZ and Forster JW (2001) Bulked AFLP analysis for assessment of genetic diversity in white clover (Trifolium repens L.) Euphytica 121:305-315.

Kozuharov S, Petrova A and Ehrendorfer S (1981) Evolutionary patterns in some brome grass species (Bromus, Gramineae) of the Balkan Peninsula. Bot Jahrb Syst 102:381-391.

Lewontin RC (1972) The apportionment of human diversity. Evol Biol 6:381-398.

Maniatis T, Fritsch EF and Sambrook J (1982) Molecular Cloning: A Laboratory Manual. Cold Spring Harbor Laboratory, Cold Spring Harbor.

Massa AN, Larson SR, Jensen KB and Hole DJ (2001) AFLP variation in Bromus section Ceratochloa germplams of Patagonia. Crop Sci 41:1609-1616.

Massa AN, Jensen KB, Larson SR and Hole DJ (2004) Morphological variation in Bromus section Ceratochloa germplasm of Patagonia. Can J Bot 82:136-144.

Matthei O (1986) The genus Bromus L. (Poaceae) in Chile. Guyana Bot 43:47-110.

Naranjo CA, Arias FH, Gil FE and Soriano A (1990) Bromus pictus of the B. setifolius complex (Section Pnigma): Nu- merical taxonomy and chromosome evidence for species rank. Can J Bot 68:2493-2500.

Newbury HJ and Ford-Lloyd BV (1993) The use of RAPD for assessing variation in plants. Plant Growth Regul 12:43-51.

Paran L, Afergoot E and Shifriss C (1998) Variation in Capsicum annum revealed by RAPD and AFLP markers. Euphytica 99:167-173.

Perez T, Albornoz J and Dominguez A (1998) An evaluation of RAPD fragment reproducibility and nature. Mol Ecol 7:1347-1358.

Puecher DI, Robredo CG, Rios RD and Rimieri P (2001) Genetic variability measures among Bromus catharticus Vahl. populations and cultivars with RAPD and AFLP markers. Euphytica 121:229-236.

Rohlf FJ (1988) NTSYS-pc. Numerical Taxonomy and Multiariate Analysis System, version 1.4. Exeter Publishers Ltd., Setauket.

Saghai-Maroof MA, Soliman KM, Jorgensen RA and Allard RW (1984) Ribosomal DNA spacer-length polymorphisms in barley: Mendelian inheritance, chromosomal location, and population dynamics. Proc Natl Acad Sci USA 80:80148018 .

Schrauf GE and Naranjo CA (1988) Relationship between environmental characteristics and isoenzymatic variation in Pappophorum (Gramineae). Genet Agric 42:391-402.

Scott AW and Whalley RDB (1984) The influence of intensive sheep grazing on genotypic differentiation in Danthonia linkii, D. richardsonii and D. racemosa on the New England Tablelands. Aust J Ecol 9:419-429.

Smith P (1970) Taxonomy and nomenclature of the brome-grasses (Bromus L.s.1.). Notes R Bot Gard Edinb 30:361-375.

Soltis DE and Soltis PS (1998) Choosing an approach and an appropriate gene for phylogenetic analysis. In: Soltis DE, Soltis PS and Doyle JJ (eds) Molecular Systematics of Plants II: DNA Sequencing. Kluwer Academic Publishers, Boston, pp $1-42$.

Stebbins GL (1947) The origin of the complex Bromus carinatus and its phytogeographic implications. Contrib Gray Herb Harv Univ 165:42-55.

Vos P, Hogers R, Bleeker M, Reijans M, Van de Lee T, Hornes M, Frijters A, Pot J, Peleman J, Kuiper M and Zabeau M (1995) AFLP: A new technique for DNA fingerprinting. Nucleic Acids Res 23:4407-4414.

Wang Z-Y, Hopkins A and Mian R (2001) Forage and turf grass biotechnology. CRC Crit Rev Plant Sci 20:573-619.

Williams JGK, Kubelik AR, Livak KJ, Rafalski JA and Tingey SV (1990) DNA polymorphisms amplified by arbitrary primers are useful as genetic markers. Nucleic Acids Res 18:6531-6535.

Wolfe AD and Liston S (1998) Contributions of PCR-based methods to plant systematics and evolutionary biology. In: Soltis DE, Soltis PS and Doyle JJ (eds) Molecular Systematics of Plants II: DNA Sequencing. Kluwer Academic Publishers, Boston, pp 43-86.

\section{Associate Editor: Marcelo Guerra}

License information: This is an open-access article distributed under the terms of the Creative Commons Attribution License, which permits unrestricted use, distribution, and reproduction in any medium, provided the original work is properly cited. 